Original studies

Somnologie $2020 \cdot 24: 253-258$

https://doi.org/10.1007/s11818-020-00282-5

Published online: 10 November 2020

(c) The Author(s) 2020

\author{
Jasmin Faber ${ }^{1}$ Indra Steinbrecher-Hocke ${ }^{2}$. Peter Bommersbach ${ }^{2}$. \\ Angelika A. Schlarb' \\ 'Universität Bielefeld, Bielefeld, Germany \\ ${ }^{2}$ Eifelklinik Manderscheid, Manderscheid, Germany
}

\title{
Does media use before bedtime affect the sleep of psychosomatic rehabilitation patients?
}

The percentage, however, decreased with age for both men and women. Only 1833 respondents were used for further statistical analysis because media use was stated as the sole cause of insufficient sleep. In $96.9 \%$ of cases, the respondent used a mobile phone less than $0.5 \mathrm{~h}$ before sleep and $74.8 \%$ of these media produced or required light. The authors additionally divided all respondents into subgroups based on the amount of time spent using media before bedtime: light users spending less than $2.5 \mathrm{~h}$, heavy users spending more or equal to $3.5 \mathrm{~h}$. Analysis showed that $29 \%$ of light users, $39.5 \%$ of intermediate users and $53.5 \%$ of heavy users perceived media use as a cause of insufficient sleep. Sleep duration on workdays, on the one hand, was significantly longer in light users than in heavy users, whereas no differences were found for non-workdays.

Later studies focused more on in-bed media use before sleep (e.g. [2, 3, 7, 8]). For example, Brunborg and colleagues [3] investigated the relationship between in-bed media use and sleep habits on weekdays and weekends/days off and symptoms of insomnia with completed data from the Norwegian national register $(N=816$; age range: $16-40$ years $)$. On weekdays respondents rose later when using a computer in bed, and turned off the light later when using their mobile phone. On weekends/days off, however, respondents rose later, turned off the lights later, and slept more hours when using a computer. Using a mobile phone led to a later time of turning off the lights and of bedtime on weekends/days off. Regarding other digital devices, e.g. television, game consoles and listening to music/radio, no significant differences were found. Media use did not affect symptoms of insomnia.

Besides the actual use of media, Custers and colleagues [7] determined the influence of the availability of internet and television in the bedroom. In faceto-face interviews, the authors gathered information about the availability and use of internet and television as well as on sleep parameters in 711 Belgian residents with a mean age of 49.35 years. Though internet availability in the bedroom was associated with a later bedtime on weekdays and at weekends, as well as a later rise time on weekdays, there was no effect of access of a TV in the bedroom. The use of internet and TV led to a later bedtime on weekends and a later rise time on weekends for internet use. Sleep duration and tiredness were not predicted by the availability and use of internet and TV.

Media use before sleep might not be the only predicting factor for insufficient sleep; night-time awakenings and media use might also be associated [8]. In an online survey, 584 adults (mean age 48.5 years, $18-96$ years) responded to various questionnaires. Results showed that social media shortly before bedtime was used by $58 \%$ on a daily basis and multiple times per week in $15 \%$. Social media use during the night was rather rare $(7.9 \%$ on a daily basis, 5.8\% 2-3 times a week), although it significantly predicted poorer sleep quality. 


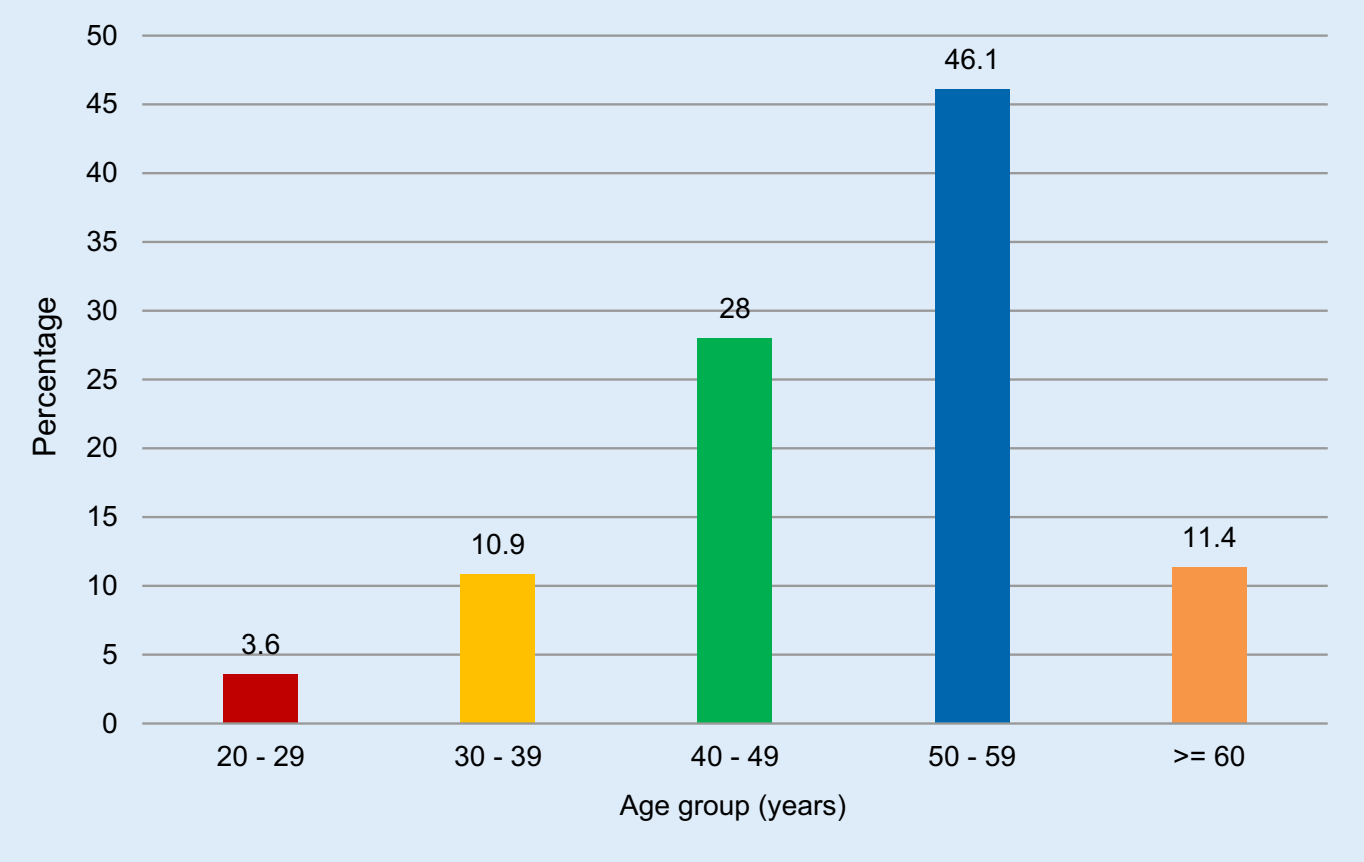

Fig. $1 \varangle$ Percentage for each age group

Occasionally, digital devices are specifically used as a sleep aid to fall asleep faster or relax. Exelmans and colleagues [9] investigated this relationship in 844 adults (mean age 46 years, 18-94 years) using face-to-face interviews. Various sleep aids had a significantly higher odds ratio when available in the bedroom: television (six times higher), videogames (ten times higher), computer (3.13) and smartphone (1.88). A computer (83.98), tablet (2.75) or smartphone (2.92.) in the bedroom led to a higher likelihood of using the internet as a sleep aid. The authors reported no significant relation to sleep duration, however, for all media types and sleep hygiene. Sleep aids, like videogames, music or internet, predicted a later bedtime and rise time.

Media use affects other factors as well, e.g. fatigue [9], daytime sleepiness, mood [2] and cognitive failures [21]. Those few results, however, suggest that media use does indeed impact one's sleep. Nonetheless, the presented studies focused on healthy adults, assessing the parameters in cross-sectional surveys or interviews. Hence, the association between media use and sleep in patients with mental disorders and sleep problems, especially in rehabilitation patients, would be of importance for research and practice.

\section{Research question}

The aim of this study was to examine the relationship between media use directly before bedtime and various sleep parameters such as sleep quality, sleep onset latency and sleep efficiency. We assumed that more media use before bedtime negatively affects sleep parameters.

\section{Methods}

\section{Procedure and sample}

Patients from a German psychosomatic rehabilitation clinic were screened for their subjective sleep quality and insomnia symptoms using questionnaires shortly after arriving. Eligible patients were then asked to complete an additional sleep log over a period of 1 week. This study was approved by the ethics committee of the State Chambers of Physicians of Rhineland-Palatinate.

A total of 347 patients fulfilled inclusion criteria of an impaired sleep quality and insomnia criteria using a screening questionnaire. Mean age was 49.77 years (standard deviation $=9.01$; median $=52$ years) and ranged from 22 to 64 years. However, data regarding age were not available from 11 patients. - Figure 1 shows the percentage for each age group; 174 male and 162 female patients participated.

\section{Instruments}

\section{Pittsburgh Sleep Quality Index}

The Pittsburgh Sleep Quality Index (PSQI) [4] was used to assess the subjective sleep quality retrospectively over the past 4 weeks. It consists of 18 items which are used for a quantitative analysis. Patients' responses are allocated to a global score, which can range between null and 21, and seven subscales: sleep quality, sleep latency, sleep duration, habitual sleep efficiency, sleep disturbances, use of sleep medication and daytime dysfunction. Global scores below six represent good sleepers, between six and ten impaired sleepers, and above ten chronic sleep disorders. Based on the reliability coefficients of 0.77 to 0.83 and high specificity and sensitivity for identifying patients with sleep disorders $(>80 \%)$, the PSQI can be classified as a valid and reliable instrument $[1,4,20]$.

\section{Insomnia Questionnaire for Adults}

The Insomnia Questionnaire for Adults (IQ-A) [16] is a screening instrument which assesses insomnia criteria based on the Diagnostic and Statistical Manual of Mental Disorders, 5th edition (DSM 5). 
Somnologie $2020 \cdot 24: 253-258$ https://doi.org/10.1007/s11818-020-00282-5

(c) The Author(s) 2020

J. Faber · I. Steinbrecher-Hocke · P. Bommersbach · A. A. Schlarb

\section{Does media use before bedtime affect the sleep of psychosomatic rehabilitation patients?}

\section{Abstract}

Objective. Media use can affect sleep. However, research regarding various populations is sparse. The objective of this study was to examine the relationship between media use directly before bedtime and various sleep parameters in patients of a psychosomatic rehabilitation clinic.

Methods. Patients from a German psychosomatic rehabilitation clinic were tested regarding subjective sleep quality and insomnia symptoms based on questionnaires such as the Pittsburgh Sleep Quality Index (PSQI). Eligible patients also completed an additional sleep log over a period of 1 week. A total of 347 insomnia patients were enrolled, with a mean age of 49.77 years (range
22-64 years; median $=52$ years). $57.5 \%$ of the patients were 50 years or older.

Results. Analysis showed that media use and various sleep diary parameters such as total sleep time $\left(r=-0.386, p=0.042 ; r_{T S T^{2}}=0.149\right)$ and sleep efficiency $(r=-0.507, p=0.006$; $r_{S E}{ }^{2}=0.257$ ) were significantly associated. In detail, more media consumption was associated with less total sleep time and a lower sleep efficiency. The same result was found for media use and sleep efficiency on weekdays $\left(r=-0.544, p=0.002 ; r_{S E}{ }^{2}=0.296\right)$, but not for other sleep parameters. However, media use time and subjective sleep quality were not significantly correlated, $r=-0.055$, $p=0.768$.
Conclusion. This study, which is the first to examine the relation between media use and sleep in patients of a psychosomatic rehabilitation clinic, suggests a significant association between media use and sleep duration as well as sleep efficiency. However, more research is needed to investigate the relationship between media use and sleep in more detail, to increase patients' quality of life and to incorporate these findings into the daily life of clinicians and therapists as well as into sleep hygiene education and sleep trainings.

Keywords

Sleep quality · Sleep efficiency · Total sleep time $\cdot$ Insomnia $\cdot$ Rehabilitation patients

\section{Beeinflusst die Mediennutzung vor dem Zubettgehen den Schlaf bei Patienten der psychosomatischen Rehabilitation?}

\section{Zusammenfassung}

Ziel. Medienkonsum kann Schlaf beeinträchtigen. Jedoch gibt es wenige Forschungsergebnisse hinsichtlich unterschiedlicher Patientengruppen. Ziel dieser Studie war es, den Zusammenhang zwischen dem Medienkonsum vor dem Zubettgehen und Schlaf bei Patienten und Patientinnen einer psychosomatischen Rehabilitationsklinik zu untersuchen.

Methoden. Patienten einer psychosomatischen Rehabilitationsklinik wurden bei der Aufnahme hinsichtlich ihrer Schlafqualität und Insomniekriterien befragt. Patienten, die über eine schlechte Schlafqualität berichteten und die Insomniekriterien erfüllten, wurden in die Studie aufgenommen und füllten ein einwöchiges Schlaftagebuch aus. Insgesamt wurden die Daten von 347 Patienten mit einem Durchschnittsalter von 49,77 Jahren
(Spannbreite: 22-64 Jahre; Median: 52 Jahre) berücksichtigt. Von den Patienten waren $57,5 \%$ über 50 Jahre alt.

Ergebnisse. Mit der Mediennutzung korrelierten die Schlafdauer $(r=-0,386$; $\left.p=0,042 ; r_{T S T^{2}}=0,149\right)$ und die Schlafeffizienz $\left(r=-0,507 ; p=0,006 ; r_{S E}{ }^{2}=0,257\right)$, gemessen mit dem Schlaftagebuch. Je mehr Medien direkt vor dem Schlafen genutzt wurden, desto geringer waren die Schlafdauer und die Schlafeffizienz. Dies galt ebenfalls für die Mediennutzung und die Schlafeffizienz an Wochentagen $\left(r=-0,544 ; p=0,002 ; r_{S E}^{2}=0,296\right)$, jedoch nicht für andere Schlafparameter. Zwischen der Mediennutzung vor dem Zubettgehen und der subjektiven Schlafqualität wurde hingegen kein signifikanter Zusammenhang gefunden, $r=-0,055 ; p=0,768$.
Schlussfolgerung. Die vorliegende Studie ist eine der ersten, die den Zusammenhang von Mediennutzung und Schlaf bei Patienten einer psychosomatischen Rehabilitation untersuchte. Die Ergebnisse zeigen, dass dieser Zusammenhang zumindest für die Schlafdauer und -effizienz signifikant ist. Zukünftige Forschung sollte dies jedoch detaillierter untersuchen, um die Lebensqualität der Patienten zu erhöhen und die Integration in den Therapiealltag sowie in Anleitungen zur Schlafhygiene und in das Schlaftraining zu erleichtern.

\section{Schlüsselwörter}

Schlafqualität · Schlafeffizienz · Schlafdauer . Insomnie · Patienten der Rehabilitation
This questionnaire consists of 11 items with a dichotomous scale (yes or no). In order to determine whether an insomnia diagnosis is fulfilled, the impairment due to and the duration of the insomnia symptoms must be present. Furthermore, at least one of the following symptoms must be present: problems initiating sleep, maintaining sleep and/or early wake up.

\section{Sleep log}

The sleep log is an instrument which assesses various sleep parameters. Patients in this study filled in a one-week sleep log. A sleep log is divided into a morning and evening section. The morning section includes eight questions regarding rising and bedtime, sleep onset latency, awakenings during the night, medication use, nightmares and restfulness. The evening section consists of ten questions regard- ing everyday coping, napping, physical activity, substance and media use, as well as the practice of relaxation techniques. Based on data from the sleep log, sleep parameters such as overall sleep duration, sleep onset latency and sleep efficiency were calculated. The number of minutes using digital devices before bedtime was used as the variable for media use. 


\section{Original studies}

Table 1 Correlations between media use and sleep parameters from sleep log

\begin{tabular}{|c|c|c|c|c|c|c|}
\hline & 1 & 2 & 3 & 4 & 5 & 6 \\
\hline 1 Media use & - & - & - & - & - & - \\
\hline $2 \mathrm{SOL}$ & 0.257 & - & - & - & - & - \\
\hline $3 \mathrm{TIB}$ & 0.003 & 0.185 & - & - & - & - \\
\hline 4 TST & $-0.386^{*}$ & $-0.392^{*}$ & $0.656^{* *}$ & - & - & - \\
\hline $5 \mathrm{SE}$ & $-0.507^{* *}$ & $-0.709^{* * * *}$ & -0.240 & $0.563^{* *}$ & - & - \\
\hline 6 WASO & 0.305 & 0.09 & 0.029 & -0.326 & $-0.518^{* *}$ & - \\
\hline
\end{tabular}

SOL sleep onset latency, TIB time in bed, TST total sleep time, SE sleep efficiency, WASO wake after sleep onset

${ }^{*} p<0.05,{ }^{* *} p<0.01$

\section{Statistical analysis}

Statistical analyses were carried out with IBM SPSS Statistics 25 (IBM Corp., Armonk, NY, USA). The $P$-value was set to $p<0.05$. Missing data were not substituted. A minimum of four nights from the sleep log was assumed as valid and eligible data. The relationship between media use and sleep parameters was verified using the Pearson correlation. Effect sizes are reported as $r^{2}$ with $r^{2}<0.10$ as a small effect, $\mathrm{r}^{2}=0.10-0.30$ as small to medium effect and $r^{2}=0.30-0.50$ as a medium to large effect. T-tests for independent samples were used for group comparisons. Hereby, the effect size Cohen's $d$ is reported $(d=0.20$ small effect, $\mathrm{d}=0.50$ medium effect, $\mathrm{d}=0.80$ large effect).

\section{Results}

\section{Sleep quality}

The total score of the PSQI and the mean time of media use were used to investigate the relationship between sleep quality and media use. There was no significant correlation between these two variables, $r=-0.055, p=0.768$.

\section{Sleep diary}

The following sleep parameters were derived from the sleep log: sleep onset latency (SOL), time in bed (TIB), total sleep time (TST), sleep efficiency (SE) and wake after sleep onset (WASO). The mean time of media use over 1 week was significantly related to TST $(r=-0.386$, $p=0.042)$ and SE $(r=-0.507, p=0.006)$. In detail, longer duration of media use be- fore bedtime was associated with a lower total sleep time. In addition, more media time was also significantly associated with lower sleep efficiency-both results with medium effect sizes $\left(r_{T S T}{ }^{2}=0.149\right.$, $\left.r_{S E}^{2}=0.257\right)$. However, media use was not significantly related to other sleep parameters such as sleep onset latency or wake after sleep onset. See • Table 1 for all correlations.

\section{Differences between weekdays and weekends}

In another step, correlations were conducted for weekdays and the weekend separately. Analysis showed a significant relation between media use and sleep efficiency on weekdays $(r=-0.544$, $p=0.002)$, which counts as a medium effect $\left(r_{S E}^{2}=0.296\right)$. More precisely, longer duration of media use was related to lower sleep efficiency during the week. Other correlations were not significant. A group comparison of media use during the week and at the weekend revealed no significant difference, $t(295)=-0.751$, $p=0.459$.

\section{Discussion}

The aim of the present study was to examine the relationship between media use directly before bedtime and various sleep parameters in a specific population. Significant relationships were found for the duration of media use before bedtime and total sleep time and sleep efficiency for the overall week. However, this was not the case for other sleep parameters, such as sleep quality, sleep onset latency, time in bed and wake after sleep onset. Furthermore, a more detailed analysis has shown the importance of media use during the week with a significant correlation of media use and sleep efficiency, though this was not found for other sleep parameters.

These findings are mostly in contrast to previous studies, which reported an effect of in-bed media use and later rise and bedtime while using a computer or smartphone [3, 7]. However, both studies showed no effect on sleep duration. On the one hand, these different results can be affiliated to the different samples. Previous studies investigated the relationship between media use and sleep in healthy individuals, whereas the study at hand focused on patients from a psychosomatic rehabilitation clinic. Most of these patients suffer from impaired sleep quality on admission $[12,18]$. Most of them even fulfilled symptoms of insomnia [18]. In addition, our sample was older than most other samples. As light sensitivity increases with age, media consumption might be kept in mind as a further and more important risk factor for persons with higher age [15].

Brunborg and colleagues [3] found in their sample that media use does not affect symptoms of insomnia; however, an impaired sleep quality and insomnia disorder were part of the inclusion criteria in the present study and therefore required for valid participation. Besides, it could be discussed that media use might not be the leading cause of psychosomatic patients' impaired sleep quality and insomnia symptoms. Other factors, e.g. physical and mental health, stress and medication, might be of more importance. Beyond this, most of our patients were older than 50 years and might therefore have multiple impairments regarding mental and physical health [13].

On the other hand, the studies by Brunborg et al. [3] and Custers et al. [7] focused on in-bed media use, whereas the study at hand did not specifically differentiate between in-bed and outside-bed media use. These circumstances might have led to the non-significant results regarding media use and sleep onset latency, and wake after sleep onset. Some patients probably used their digital devices outside of the bed and other factors have more influence on patients' sleep. 
Hier steht eine Anzeige.

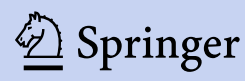


Furthermore, in our patients, the motive of media use might also have been to avoid worries and rumination, which is typical for insomnia patients and might use therefore media as a form of distraction. As media usage was associated with a shorter total sleep time, this point has to be kept in mind when treating inhouse patients. A short sleep in the age group 55 years and above with less than $7 \mathrm{~h}$ is declared as a risk factor for other diseases and higher mortality [13].

\section{Limitations}

There are several limitations to this study. First, data on media use before bedtime was collected via a sleep log. Based on this method, information about media use measured objectively [6], the type of media, the place of media use (in bed vs. outside) and the effect of blue light [10, 17] is missing. Secondly, this study focused on patients already suffering from impaired sleep quality and insomnia. Although it is one of the first studies to examine the relation between media use and sleep in patients of a rehabilitation clinic, there might be other factors which should be taken into account.

\section{Conclusion}

Despite the limitations, the present study is the first to examine the relationship between media use and sleep in patients of a psychosomatic rehabilitation clinic. The results showed that in these patients, media use is significantly associated with impaired sleep duration and efficiency, which is often associated with reduced quality of life of the patients. Therefore, media consumption should also be assessed in psychosomatic rehabilitation patients-despite other aspects of diseases. Therefore, for treatment of insomnia in rehabilitation patients, these factors should be kept in mind and might be adapted for special disorders (for example for pain disorders) [14]. However, more research is needed to investigate the relationship between media use and sleep in more detail and to incorporate these findings into the daily life of clinicians and therapists, as well as into sleep hygiene education and sleep trainings.

\section{Corresponding address}

Prof. Dr. Angelika A. Schlarb

Universität Bielefeld

Universitätsstraße 25, 33501 Bielefeld,

Germany

angelika.schlarb@uni-bielefeld.de

Funding. This study was funded by the Rehabilitations-Forschungsnetzwerk. Open Access funding enabled and organized by Projekt DEAL.

\section{This study was conducted in compliance with ethical guidelines}

Conflict of interest. J. Faber, I. Steinbrecher-Hocke, P. Bommersbach and A. A. Schlarb declare that they have no competing interests.

All procedures performed in studies involving human participants or on human tissue were in accordance with the ethical standards of the institutional and/or national research committee and with the 1975 Helsinki declaration and its later amendments or comparable ethical standards. Informed consent was obtained from all individual participants included in the study.

Open Access. This article is licensed under a Creative Commons Attribution 4.0 International License, which permits use, sharing, adaptation, distribution and reproduction in any medium or format, as long as you give appropriate credit to the original author(s) and the source, provide a link to the Creative Commons licence, and indicate if changes were made. The images or other third party material in this article are included in the article's Creative Commons licence, unless indicated otherwise in a credit line to the material. If material is not included in the article's Creative Commons licence and your intended use is not permitted by statutory regulation or exceeds the permitted use, you will need to obtain permission directly from the copyright holder. To view a copy of this licence, visit http://creativecommons.org/licenses/by/4.0/.

\section{References}

1. Backhaus J, Junghanns K, Broocks A, Riemann D, Hohagen F (2002) Test-retest reliability and validity of the Pittsburgh Sleep Quality Index in primary insomnia. J Psychosom Res 53:737-740

2. Bhat S, Pinto-Zipp G, Upadhyay H, Polos PG (2018) "To sleep, perchance to tweet": in-bed electronic social media use and its associations with insomnia, daytime sleepiness, mood, and sleepduration in adults. SleepHealth 4(2):166-173

3. Brunborg GS, Mentzoni RA, Molde H, Myrseth $\mathrm{H}$, Skouverøe KJM, Bjorvatn B, Pallesen S (2011) The relationship between media use in the bedroom, sleep habits and symptoms of insomnia. J Sleep Res 20(4):569-575

4. Buysse DJ, Reynolds CF III, Monk TH, Berman SR, Kupfer DJ (1989) The Pittsburgh Sleep Quality Index: a new instrument for psychiatric practice and research. Psychiatry Res 28:193-213
5. Cain N, Gradisar M (2010) Electronic media use and sleep in school-aged children and adolesents: A review. Sleep Med 11:735-742

6. Christensen MA, Bettencourt L, Kaye L, Moturu ST, Nguyen KT, Olgin JE, Pletcher MJ, Marcus GM (2016) Direct measurements of smartphone screen-time: relationships with demographics and sleep. PLoS ONE 11(11):e165331

7. Custers K, van den BulckJ(2012) Television viewing, internet use, and self-reported bedtime and rise time in adults: implications for sleep hygiene recommendations from an exploratory crosssectional study. Behav Sleep Med 10(2):96-105

8. Exelmans L, Scott H (2019) Social media use and sleep quality among adults: the role of gender, age and social media checking habit. PsyArXiv. https:// doi.org/10.31234/osf.io/eqxdh

9. Exelmans L, van den Bulck J (2016) The use of media as a sleep aid in adults. Behav Sleep Med 14(2):121-133

10. Green A, Cohen-Zion M, Haim A, Dagan Y (2017) Evening light exposure to computer screens disrupts human sleep, biological rhythms, and attention abilities. Chronobiol Int 34(7):855-865

11. Levenson JC, Shensa A, Sidani JE, Colditz JB, Primack BA (2016) The association between social media use and sleep disturbance among young adults. Prev Med 85:36-41

12. Linden M (2015) Institutional prevalence and context of severe sleep disorders in psychosomatic rehabilitation. Psychother Psychosom Med Psychol 65:268-272

13. Netzer N, Pramsohler S, Frohnhofen H(2018) Schlaf beim alten Menschen. Somnologie 22:240-244

14. Richter K, Miloseva L, Köck M, Hillemacher T, Weeß HG (2018) Verhaltenstherapeutische Behandlung von Insomnie im Alter - wann und wie behandeln? Somnologie 22:245-250

15. Rubiño JA, Gamundí A, Akaarir M, Cañellas F, Rial R, Ballester N, Nicolau MC (2017) Effects of differences in the availability of light upon the circadian rhythms of institutionalized elderly. Chronobiol Int 34:1197-1210

16. Schlarb AA, Faber J (2020) Insomnia Questionnaire for Adults (IQ-A)

17. Šmotek M, Fárková E, Manková D, Kopřivová J (2020) Evening and night exposure to screens of media devices and its association with subjectively perceived sleep: Should "light hygiene" be given more attention? Sleep Health 6(4):498-505

18. Steinbrecher-Hocke I, Faber J, Bommersbach P, Schlarb AA Unruhige Zeiten: Psychische Belastung und Schlafqualität bei Patienten in der stationären psychosomatischen Rehabilitation (in press)

19. Suganuma N, Kikuchi T, Yanagi K, Yamamura S, Morishima H, Adachi H, Kumano-Go T, Mikami IA, Sugita Y, Takeda M (2007) Using electronic media before sleep can curtail sleep time and result in selfperceived insufficient sleep. Sleep Biol Rhythms 5(3):204-214

20. Tsai PS, Wang SY, Wang MY, Su CT, Yang TT, Huang CJ, Fang SC (2005) Psychometric evaluation of the Chinese version of the Pittsburgh Sleep Quality Index (CPSQI) in primary insomnia and control subjects. Qual Life Res 14:1943-1952

21. Xanidis N, Brignell CM (2016) The association between the use of social network sites, sleep quality and cognitive function during the day. ComputHuman Behav 55:121-126 